\title{
Rising Internet Use, Generational Effects, and Changing Patterns of Political Participation in East Asia
}

\author{
Yi Chen \\ School of Public Affairs \& Law, Southwest Jiaotong University, China
}

Keywords: Internet, generation, political participation, activist participation, electoral participation.

\begin{abstract}
This paper examines how regular Internet use affects patterns of political participation, and whether this relationship is consistent across different generations, by using the data from the 3rd wave of the Asian Barometer Survey (ABS). Furthermore, Internet use is associated with lower level of participation, but there is a difference among different generations (under - 35s and over 35s). It is suggested that as Internet use becomes universal across different age groups, its effect on patterns of political participation will decline.
\end{abstract}

\section{Introduction}

The rapid rise of the Internet in recent decades has potentially revolutionary effects for participation in politics. Around the globe, use of the Internet has become a major factor in political mobilization that challenges incumbent regimes around the world (Karatnycky, 2005; Grossman, 2009; Khondker, 2011). However, despite the widespread media reporting of the role of the Internet in political mobilization, there is still no consensus among scholars on the relationship between Internet use and political participation. Some scholars (Tolbert and Mcneal, 2003; Zúñiga, Jung, and Valenzuela, 2012) find that Internet use is associated with increased voting and political participation beyond voting. However, other scholars have found that Internet use does not lead to greater participation (Davis, 1999; Bimber, 2001). Furthermore, the effects of Internet use on political participation varies with the type of activity and may be mediated by various contextual factors (Quintelier and Vissers, 2008; Wang, 2007). With the growth of Internet use in East Asia, it is necessary to establish whether their findings also apply in Asian social and political contexts.

This article is organized as follows. In the section below, we present an overview of rising Internet use in East Asia and examine the relationship between Internet use and patterns of political participation in the context of the existing literature. We then present our findings using data from the third wave of the Asian Barometer Survey (ABS). Finally, we discuss the implications of our findings.

\section{Rising Internet Use and Patterns of Political Participation in East Asia}

The Internet did not achieve mass adoption until the last decade. The mass adoption of the Internet has been driven a number of important advances in hardware technology, most notably high-speed broadband and wireless Internet access as well as mobile device technology (Cowhey and Aronson, 2012). At the same time, software interfaces have become increasingly user-friendly, enabling consumers to use devices to access the Internet with minimal effort and without any prior knowledge or expertise (Paasonen, 2010: 414). Most critically, the falling costs of Internet access together with rising incomes is putting the technology within the reach of increasing numbers of people, reaching a 36.9\% penetration rate in the Asia-Pacific region by 2015 (Internet Telecommunications Union, 2015).

As Internet use becomes increasingly universal across generations, social class, and outside urban areas, groups that have not previously participated in the Internet revolution will begin to get online. Therefore, as the online population grows, it is increasingly important to understand how this dramatic change is affecting patterns of political participation. Will growing online political 
participation challenge incumbent regimes, as has been seen in protest movements ranging from the Arab Spring to anti-government protests in Malaysia and Cambodia? In addition, can we find differences between generations in the relationship between Internet use and political participation?

\section{Data and Measures}

This article uses the latest wave of data from the Asian Barometer Survey (ABS III, 2010-2012) in East and Southeast Asia. In order to ensure survey samples are representative, in each surveyed country stratified multistage probability proportional to size (PPS) sampling of voting aged adults was carried out. A standard questionnaire instrument was administered in all countries to ensure cross-national comparability. First, we present descriptive statistics on the numbers of regular Internet users across four different age groups: aged 17-35, aged 36-50, aged 51-65, and aged 65 and over. When reporting regular Internet use, we also distinguish between countries with different levels of economic development according to GDP per capita in the year of the survey (above US\$20,000, US\$3,000-10,000, and under US\$3,000). Second, we carry out a correlation analysis with betweenand within-cohort variation to assess the relationship between Internet use and patterns of political participation. Finally, to assess the effect of age in the relationship between regular Internet use and patterns of political participation, we distinguish between youth (aged 17-35) and older generations (aged 36 or over). For the independent and dependent variables, we use the following items from the ABS.

\section{Internet Use}

Respondents are asked the following question: "How often do you use the Internet?" Responses were as follows: (1) almost daily; (2) at least once a week; (3) at least once a month; (4) several times a year; (5) hardly ever; (6) never. Respondents who used the Internet "almost daily" or "at least once a week" were classified as regular Internet users.

\section{Political Participation}

We distinguish between two types of political participation: electoral and activist. To measure electoral participation, we use the following item: "In talking to people about elections, we often find that a lot of people were not able to vote because they were away from home, they were sick or they just didn't have time. How about you? Did you vote in the election [the most recent national election, parliamentary or presidential] held in [year]?" Responses to this item are binary, distinguishing whether a respondent voted or not. To measure activist participation, citizens are asked if they have done the following never, once, or more than once during the past three years: (1) "Got together with others to raise an issue or sign a petition"; (2) "Attended a demonstration or protest march." If a respondent has engaged in either of the two actions "once" or "more than once" over the past three years, then their responses are coded as 1 , otherwise 0.

\section{Results}

Data from the third wave of the ABS show that the distribution of regular-user percentage (respondents who use the Internet at least once a week) by age cohort show very similar patterns for each of the countries within the each of the three income brackets. In the five advanced economies with per capita GDP of over US\$20,000, with around 90\% of young people aged 17-35 self-reported regular Internet use, compared to around two-thirds of respondents aged 36-50, and more than one-third of respondents aged 51-65. However, Internet penetration among the senior group of respondents aged 65 or over remained low, exceeding $10 \%$ in only one country (Japan). Of the middle income countries, the country with the highest GDP per capita, Malaysia, had Internet penetration rates of $63 \%$ among the youth age cohort, compared to $30 \%$ among the $36-50$ age group, $17 \%$ among the 51-65 age group, and only 6\% among the over 65 age group. These figures for Internet penetration 
were somewhat higher than for other lower income countries within the group, which ranged from between 25\% (Indonesia) to 46\% (Mongolia) for young people, and was around $20 \%$ or less for all other age groups. Finally, even in the countries in the lowest income bracket, significant numbers of young people are also regular Internet users, with $25 \%$ and $38 \%$ of young people in the Philippines and Vietnam respectively reporting regular Internet use. Cambodia was the only outlier, with only $7 \%$ of young people reporting regular Internet use.

Table 1 Percentage of regular Internet Users across East Asia, by age cohorts, on surveyed years ${ }^{a}$

\begin{tabular}{l|lllll|lllllllll}
\hline $\begin{array}{l}\text { Age } \\
\text { Cohorts }\end{array}$ & \multicolumn{3}{|l|}{ GDPpc above \$20000 USD } & & \multicolumn{3}{|l|}{ GDPpc \$3000-10000 USD } & & \multicolumn{3}{l}{ GDPpc Below \$3000 } \\
& SGP & JPN & HKG & KOR & TWN & MAL & CHN & THA & IND & MON & PHI & VIE & CAM \\
\hline $17-35$ & $92 \%$ & $88 \%$ & $97 \%$ & $97 \%$ & $93 \%$ & $63 \%$ & $53 \%$ & $32 \%$ & $25 \%$ & $46 \%$ & $25 \%$ & $38 \%$ & $7 \%$ & \\
$36-50$ & $69 \%$ & $78 \%$ & $71 \%$ & $81 \%$ & $56 \%$ & $30 \%$ & $20 \%$ & $10 \%$ & $7 \%$ & $23 \%$ & $8 \%$ & $25 \%$ & $1 \%$ & \\
$51-65$ & $39 \%$ & $54 \%$ & $36 \%$ & $41 \%$ & $33 \%$ & $17 \%$ & $9 \%$ & $7 \%$ & $6 \%$ & $20 \%$ & $6 \%$ & $14 \%$ & $0 \%$ \\
$66+$ & $5 \%$ & $17 \%$ & $7 \%$ & $5 \%$ & $9 \%$ & $6 \%$ & $4 \%$ & $1 \%$ & $1 \%$ & $6 \%$ & $4 \%$ & $10 \%$ & $0 \%$ \\
Overall & $63 \%$ & $59 \%$ & $61 \%$ & $68 \%$ & $55 \%$ & $39 \%$ & $27 \%$ & $13 \%$ & $12 \%$ & $34 \%$ & $14 \%$ & $25 \%$ & $4 \%$ \\
\hline
\end{tabular}

${ }^{a}$ Surveyed years: 2010 for SGP, TWN, THA,MON, PHI, and VIE; 2011 for JPN, KOR, MAL, CHN, and IND; 2012 for HKG and CAM.

Data Source: ABS III (2010-2012) for Regular Internet Use, WDI (2011) and National Statistics R.O.C. Taiwan (2011) for GDPpc

GDPpc: GDP per capita (current US\$)

Figure 1 shows the correlation coefficients for the relationship between regular Internet use and political participation for the overall sample as well as the thirteen countries and regions. The general finding is very consistent - in both the overall sample as well as the thirteen country samples, those who use the Internet regularly are less likely to participate in elections; furthermore, in the overall sample, as well as nine of the thirteen countries, regular Internet users were more likely to participate in political activism.

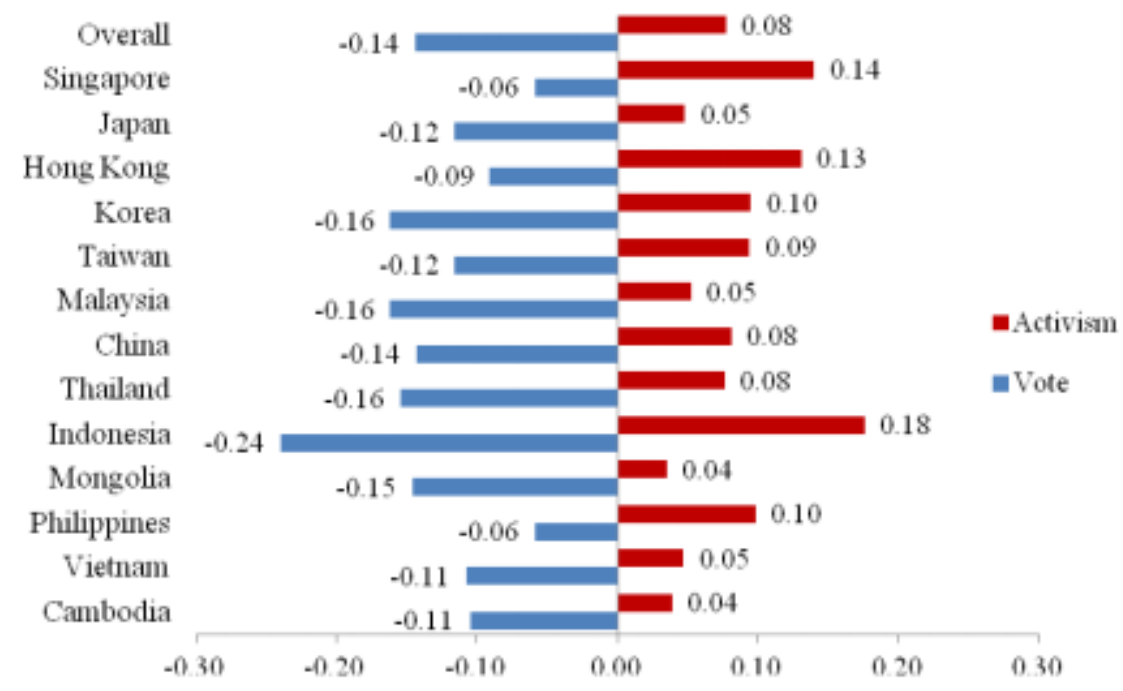

Figure 1 Correlations of Regular Internet Use on Electoral and Activist Participation in politics, by overall and country samples

Due to the association between age and patterns of political participation, a separate evaluation of the potential impact of Internet usage on political participation within generational cohorts can offer precise information on causal inference. In other words, does the association between regular Internet use and electoral and activist participation apply within different age cohorts? First, we present descriptive statistics on levels of electoral participation and activist participation in the surveyed countries. As Table 2 shows, in absolute terms, levels of electoral participation among young people are significantly lower than among the older generations (70\% vs. 87\%), while levels of activist 
participation are much lower overall than electoral participation, and show no significant difference between generations (15\% for young people, $16 \%$ for older generations).

When looking at the effect of regular Internet use on electoral and activist participation by age cohort, we find the effect is significantly weakened. Especially, electoral participation only had a statistically significant negative effect on electoral participation among young people in six of the thirteen countries surveyed, and had a statistically significant negative effect among the older generations. Furthermore, among young people, regular Internet use had a statistically significant positive effect on activist participation in just three of the thirteen countries surveyed. However, among the older generation, Internet use continued to have a significant positive effect on activist participation in nearly all surveyed countries. These findings show the relationship between Internet use and electoral and activist participation is actually a composite effect that combines Internet use and generational effects (between-cohort variance).

Table 2 Between- and Within-Country Effects of Regular Internet Use on Electoral and Activist Participation in Politics, by Age Cohort

\begin{tabular}{lll}
\hline & Youth Cohort & Older Cohort \\
\hline & Electoral Participation & \\
Overall Mean Level & $70 \%^{\mathrm{a}}$ & $87 \%^{\mathrm{a}}$
\end{tabular}

\begin{tabular}{|c|c|c|}
\hline $\begin{array}{l}\text { Country Correlation with } \\
\text { Internet Use }\end{array}$ & $\begin{array}{l}\text { Negative:6/13 }{ }^{\mathrm{b}} \\
\text { Nonsignificant:7/13 }\end{array}$ & $\begin{array}{l}\text { Negative:3/13 } \\
\text { Nonsignificant:10/13 }\end{array}$ \\
\hline Overall Mean Level & $\begin{array}{l}\text { Activist Participation } \\
15 \%{ }^{\mathrm{d}}\end{array}$ & $16 \%^{\mathrm{d}}$ \\
\hline $\begin{array}{l}\text { Country Correlation with } \\
\text { Internet Use }\end{array}$ & $\begin{array}{l}\text { Positive:3/13 } \\
\text { Nonsignificant:10/13 }\end{array}$ & $\begin{array}{l}\text { Positive:12/13 }{ }^{\mathrm{f}} \\
\text { Nonsignificant:1/13 }\end{array}$ \\
\hline \multicolumn{3}{|c|}{$\begin{array}{l}\text { a Significantly different at the } \mathrm{p}<0.05 \text { level. All } 13 \text { country cases show unanimous results that the youth } \\
\text { have lower level of electoral participation. } \\
{ }^{\mathrm{b}} \text { Hong Kong, China, Thailand, Indonesia, Mongolia, Vietnam } \\
{ }^{\mathrm{c}} \text { Korea, Indonesia, Mongolia } \\
{ }^{\mathrm{d}} \text { Non-significantly different at the }<<0.05 \text { level. Out of } 13 \text { country cases, } 10 \text { show that the youth and older } \\
\text { generations have no significant difference on the level of activist participation. } \\
\text { e Japan, Indonesia, Philippines } \\
\text { f Singapore, Japan, Hong Kong, Korea, Taiwan, Malaysia, China, Thailand, Indonesia, Mongolia, } \\
\text { Philippines, Vietnam } \\
\text { Data Source: ABS III (2010-2012) }\end{array}$} \\
\hline
\end{tabular}

\section{Discussion and Conclusion}

The much weakened negative relationship between Internet use and voting in elections within both cohorts of the under 35s and over 35s suggests that the within-cohort effect cannot solely account for the negative relationship between Internet use and electoral participation. Therefore, the overall effect must also account for the generational effect associated with the much lower turnout rate among young people compared to the higher turnout rate for the older population. Furthermore, no countries showed a statistically significant positive relationship between Internet use and electoral participation for either the under 35 or over 35 age cohorts. This demonstrates that in East Asia, regular Internet users may actually have less confidence in traditional channels of political participation, meaning that the mechanisms driving higher electoral participation among regular Internet users in Western countries do not apply in East Asia.

At the same time, no significant generational difference can be concluded from the between-cohort comparison of activist participation among the under 35s or over 35s. Nor can we find a consistent 
and significant positive relationship across the thirteen countries (this relationship was only found in three countries) among the under 35 age cohort. Both findings suggest that most of the positive relationship between Internet use and activist participation in the overall sample results from the positive within-cohort effect among the over 35s. In fact, out of the thirteen countries, twelve show that regular Internet users have a greater level of activist participation among the over 35 age cohort, confirming, unlike the negative composite effect of Internet use on electoral participation, there is a positive composite effect of Internet use on activist participation among the over 35s. In short, the nature of the shifting preference from electoral to activist participation is a heterogeneous synthetic result based on the generation effect associated with the decrease in youth electoral participation on the one hand, and an Internet-driven effect associated with the increase in activist participation among the older population on the other.

For young people, the Internet has become a dominant mode of social communication. While the Internet may provide a convenient medium to follow political news or facilitate political participation, there are many things to do online aside from politics. As a result, the use of the Internet for political purposes may be largely confined to people who are already interested in politics. At the same time, regular Internet users may find traditional modes of political participation cumbersome and unresponsive. This explains the relatively low rate of electoral participation among regular Internet users, as well as the lack of a significant relationship between regular Internet use and activist participation, despite the frequent media references to protest movements mobilized by "tech savvy" youth. On the contrary, for the older generations, the consistent relationship between regular Internet use and greater activist participation may be attributable to the costs involved in getting online for the older generations. For the older generations, Internet use is still far from universal and those who take the time and effort to learn how to use the Internet in later life may be already be more civically engaged and therefore motivated to pursue social activism through online mobilization. Internet use for this group of people may be more purposive than habitual, and therefore, contrary to our expectations, Internet use actually has a consistent positive effect on activist engagement only among older respondents, challenging the narrative of youth-dominated online mobilization.

The major finding of this research shows changing patterns of political participation in East Asia are associated with rising Internet use, specifically a shifting preference from electoral to activist participation. However, a careful interpretation of the two composing effects, paradoxically, leads to a quite contrary conclusion. As the current youth cohort grow older, generational differences in the level of Internet use will gradually disappear, and as a result, the negative relationship between Internet use and electoral participation is likely to fade away. At the same time, Internet use will become increasingly habitual rather than purposive. In short, the changing patterns of political participation may be only a temporal phenomenon that will no longer be apparent in the future when generational replacement proceeds to the extent that the Internet is a regular part of the everyday lives of citizens across all age cohorts.

\section{References}

[1] Bimber, B. (2001). Information and political engagement in America: The search for effects of information technology at the individual level. Political Research Quarterly, 54(1), 53-67. http://doi.org/10.1177/106591290105400103

[2] Cowhey, P. F., \& Aronson, J. D. (2012). Transforming global information and communication markets: the political economy of innovation. Cambridge, Mass: The MIT Press.

[3] Davis, R. (1999). the web of politics: the internet's impact on the American political system. New York: Oxford University Press.

[4] Everett, Silas. 2014. "Cambodia's Smartphone Revolution: Think Promise Not Peril." The Asia Foundation. December 3. http://asiafoundation.org/2014/12/03/cambodias-smartphone-revolution -think-promise-not-peril/.

[5] Grossman, L. (2009). Iran protests: Twitter, the medium of the movement. Time Magazine, 17. 
Retrieved from http://www.cc.gatech.edu/classes/AY2015/cs4001_summer/documents/Time-IranTwitter.pdf

[6] International Telecommunication Unions. (2015). ICT Facts and Figures, 2015. Retrieved from http://www.itu.int/en/ITU-D/Statistics/Documents/facts/ICTFactsFigures2015.pdf

[7] Karatnycky, A. (2015, September 15). Ukraine's Orange Revolution. Retrieved March 29, 2016, from https://www.foreignaffairs.com/articles/russia-fsu/2005-03-01/ukraines-orange-revolution

[8] Khondker, H. H. (2011). Role of the new media in the Arab Spring. Globalizations, 8, 675-679. http://doi.org/10.1080/14747731.2011.621287

[9] Paasonen, S. (2010). Trouble with the commercial: internets theorized and used. In J. Hunsinger, L. Klastrup, \& M. M. Allen (Eds.), International Handbook of Internet Research (2010 edition). Dordrecht; New York: Springer.

[10]Wang, S.-I. (2007). Political use of the Internet, political attitudes and political participation. Asian Journal of Communication, 17(4), 381-395. http://doi.org/10.1080/01292980701636993 